Gynäk. Rdsch. 1978;18:157-159

\title{
Contents, Vol. 18, No. 3-4, 1978
}

\section{Inhaltsverzeichnis}

Mall-Haefeli, M,: Begrüssung

161

Andor, J.: Pharmakologie und klinische Anwendung von Gestagen-Depot-Präparaten .

Bonte, J.: Effets bénéfiques de la medroxyprogesterone à dose contraceptive et à forte dose dans la prevention et le traitement des affections hyperplasiques de Гutérus . 172 Revaz, C; Welti, H. et Dettling, A.: Contraception par Tinjection trimestrielle de Depo-Provera 183

Hauser, G.A.: Ovulationshemmer bei der Frau um 40 ?

193

Dallenbach-Hellweg, G.: Häufigkeit von Spontanaborten mit und ohne vorherige Einnahme von Ovulationshemmern anhand morphologischer Untersuchungen .... 213 Bonte, J.: Effets secondaires de la contraception hormonale sur les seins 220 Werner-Zodrow, I. und Staub, J.J.: „Pille” und endokrine Erkrankungen 246 Mall-Haefeli, M.: Das Progestasert-System 253

Ludwig, K.S.: Morphologische Veränderungen an Tube und Endometrium unter dem Progestasertsystem 263

Autorenindex 266 Inhaltsverzeichnis Vol. 18 nach 266 